\title{
Strategies for Teaching a Novel Approach to Handling Uncertainty Scientifically via Internet
}

\author{
doi:10.3991/ijet.v4i2.694 \\ Xiaomin Zhai, Elart von Collani \\ Würzburg University, Würzburg, Germany
}

\begin{abstract}
More than 300 years ago Jakob Bernoulli made an attempt to initiate and to develop the Science of Prediction, which is in Latin Ars conjectandi and in Greek Stochastike. The aim of Bernoulli's stochastics is not to discover "truth", but to make reliable and accurate predictions as the basis for making appropriate decisions. Only recently, Jakob Bernoulli's plan of a Science of Prediction was resumed by Elart von Collani, who further developed it to a unified theory of uncertainty. In this paper, an effective online environment is presented and discussed for fostering the fundamental ideas of Bernoulli's stochastics and the techniques developed within this new scientific approach.
\end{abstract}

Index Terms-Bernoulli Stochastics, Online Education, Virtual Classroom

\section{The Stochastikon Project}

The term "stochastics" was introduced by Jakob Bernoulli about 300 years ago in his masterpiece Ars conjectandi [1], which was published posthumously by Jakob's nephew Nikolaus Bernoulli in 1713. Stochastics stands for a new science, which does not aim at detecting "truth", but at making reliable and accurate predictions. However, after Jakob Bernoulli had passed away in 1705, the term stochastics fell soon into oblivion together with the term also Bernoulli's plan of developing a science of prediction. In [2] the situation is described as follows: "In place of Stochastics, the science of prediction, came two other disciplines to seemingly fill the gap. These disciplines were probability theory and statistics. The word 'stochastics' survived in the term 'stochastic processes', which is used to name a special branch of probability theory." About twenty years ago, Bernoulli's stochastics was taken up by the research group of von Collani at the University of Würzburg. The research project was called Stochastikon ${ }^{1}$ and it was decided to be realized based on modern information technologies. In 2004 , the research results were published in two seminal papers $[2,3]$ (see also [6]), which define a new science termed here as Bernoulli Stochastics. An establishment of Bernoulli Stochastics would have far-reaching consequences not only for science, but also for the entire human society, because stochastics requires a change in the way of thinking. Instead of "logical" causal thinking, a holistic, stochastic thinking becomes necessary. This change in the pattern of thinking constitutes a difficult challenge for the dissemination and the establishment of Bernoulli Stochastics, and it was decided to meet the change by developing an E-Learning programme named Stochastikon Magister.

Besides, there were other problems to overcome. One of these refers to the mathematical difficulty of the new approach, which involves new methods and models and cannot be based on well-known concepts.

In order to meet the resulting mathematical challenge, a research project was established about ten years ago aiming at developing a special computer algebra system capable for solving the new problems. This stochastic computer algebra system called Stochastikon Calculator has been designed and operates although so far with a limited range. Besides the computer algebra system and the E-Learning programme Stochastikon Magister being the topic of this paper, there are three more systems, which are developed in the framework of Stochastikon. The first one is called Stochastikon Graphics, which in cooperation with Stochastikon Calculator provides graphical representations of the calculated results. Moreover, there is Stochastikon Encyclopedia representing a cross-linked work of reference for Bernoulli Stochastics and science, while the last one is named Stochastikon Mentor and represents a web-based diagnosis and consultancy tool for application.

Bernoulli Stochastics constitutes a new approach to uncertainty, which is not a part of the general education and, therefore, teaching cannot be based on existing textbooks, on available courses and on skilled teachers. However, the greatest challenge refers to the way of thinking required by Bernoulli Stochastics, which is in contrast to the traditional education. A possible criticism that the approach might be too complicated for application is proved to be wrong in [8], which describes in detail a successful industrial application of Bernoulli Stochastics. Moreover, in [7] the differences between statistical and stochastic methods are illustrated by two examples.

\section{BeRNOULli StOCHASTICS}

For a better understanding of Bernoulli Stochastics, a brief look at traditional science is necessary. All branches of exact science are based on a set of axioms, from which scientific theories are logically deduced and subsequently considered and taught as "true" natural laws. In some branches of science (e.g. physics) these axioms are trashed or amended as soon as they have proved to be incompatible with observations. In other branches (e.g. economics) the axioms supersede empirical observations and become thus similar to religious dogmas. The underlying aim of these branches of science is not to describe the observed randomly varying nature, but to

\footnotetext{
http://www.stochastikon.com/
} 
identify an assumed unobservable nature obeying deterministic laws.

In contrast, Bernoulli Stochastics aims at describing the observable nature and this is tantamount to modeling the inherent uncertainty of future developments quantitatively. The sources of human uncertainty are ignorance, which is a characteristic for mankind and randomness, which is a characteristic for the universe. Both are taken into account by Bernoulli Stochastics, thereby making reliable and at the same time accurate descriptions of the future indeterminate developments possible. Unlike probability theory, Bernoulli Stochastics is not based on the probability space, which is a purely mathematical concept, but on a realistic image of a given situation and it differs from statistics, e.g. by the very fact that it is not based on the statistical estimation and test theory.

\section{WEB-BASED E-LEARNING}

There are many types of web-based E-Learning products, but almost all of them have one feature in common: they are developed and used as supplements for traditional classroom teaching in well established fields of teaching. This holds especially for E-Learning programs in mathematical subjects, which are offered at universities in increasing number. Most of them contain materials for exercises and case studies, where students can practice certain abilities taught in regular courses. A characteristic feature of these programs is the fact that they do not need special mentoring, but operate almost completely automatically. This makes sense, if besides the Internet programme, there are regular or irregular classes offered and this implies that the subject of the E-Learning programme is well established.

Things look different for an area of teaching, which so far has not been established and, thus, is not part of the curricula of general education. Without the Internet, establishment and dissemination of such newly developed areas would take decades. However, by means of the Internet such new teaching areas can be disseminated immediately and eventually established, if the following two conditions are met:

- The new scientific area has to be prepared in a didactically appropriate way, as otherwise a successful establishment would be impossible.

- The E-Learning programme must offer an as complete as possible usable and learnable environment, including the entire list of possibilities of getting individual support within traditional classroom teaching

In other words, an E-Learning programme for a newly developed teaching area does not aim at supporting an already existing education system by means of advanced modern information technology, but to substitute the traditional educational facilities. These two aims are different and, therefore, the requirements to be met for the two types of E-Learning programmes must be different, as well.

\section{Strategies For StochastiKon Magister}

\section{A. Problems and Requirements}

An E-Learning system should not be developed independently of the knowledge to be imparted. Therefore, both problem areas must be considered concurrently, i.e. the development of the content of the curriculum in Bernoulli Stochastics and the development of an associated E-Learning environment have to take place simultaneously in order to ensure the conformance between the content and the IT realization. Thus, the development of a preliminary content of the curriculum in Bernoulli Stochastics was identified as a crucial prerequisite for the development of Stochastikon Magister.

Besides, a close cooperation among the different components of the overall Stochastikon system is required. Being a part of the master system, the E-Learning system should be able to communicate and take advantage of the existing components and of any future component of Stochastikon.

At the beginning of the project in 2004 a comprehensive literature and Internet survey on ELearning programmes in scientific areas was performed resulting in the decision that none of the existing platforms for developing an E-Learning programme should be used.

The above described situation at the outset of the project to develop an E-Learning programme for Bernoulli Stochastics was insofar unique as there was no basis, neither on the side of E-Learning nor on the side of the curriculum the programme could rest on. As a consequence, the work on Magister was started without a blueprint with respect to the curriculum and without a prototype or development toolkit for solving the problem of the IT part.

TABLE I.

THE AUTHORITY STRUCTURE IN STOCHASTIKON MAGISTER

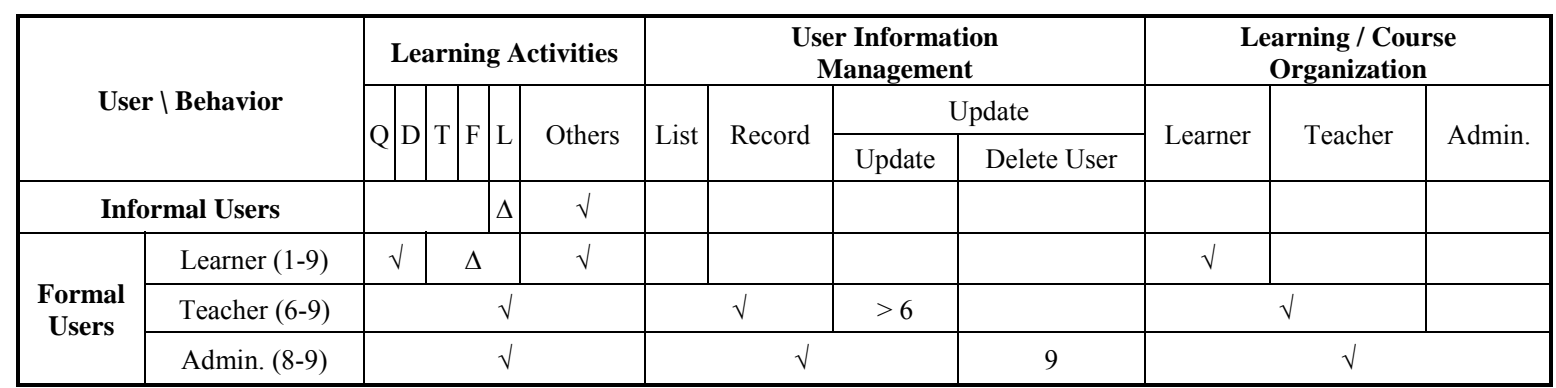

Learning activities: $\mathrm{Q}=$ Question, $\mathrm{D}=$ Discussion, $\mathrm{T}=$ Test, $\mathrm{F}=\mathrm{FAQ}, \mathrm{L}=$ Literature, Others = Introduction, Target, Content, Example and Exercise.

Numbers in the table (from 1 to 9 ) stand for the user status.

$\sqrt{ }=$ available, $\Delta=$ partly available.

Admin. $=$ Administrator. 


\section{B. The Virtual Classroom}

A complete learning organization may be omitted when an E-Learning programme is a supplement for an existing educational system. But it is necessary when learning has to be accomplished in a purely virtual environment, especially if the subject is totally new and complex. Here the word 'Learning Organization System' is used instead of the traditional 'Learning Management System', as it is an organizer and a supporter rather than just a controller in the Stochastikon Magister running process.

1) Authorities and Activities

Magister adopts a socialized mechanism and humanized mode to organize and provide services for the Stochastics teaching-learning process.

- Different authorities, responsibilities and rules of behaviors are defined in Magister by the user status called organization by status

- In Magister, any registered user does not only adopt one specific role, but can adopt different roles on different conditions. This is called role behavior. The roles with respect to task, authority and responsibility are restricted either by the user status and the activity on hand, or by other user specifics like group or study-level.

- Roles belonging to different categories, for instance Learner, Teacher, Administrator and the Magister Master, have completely different tasks. The higher authority role-category automatically possesses the rights of the lower roles. Roles in one category, but with different status, have different rights.

Table 1 lists a part of the relationships among different authorities, roles and the corresponding rights for executing operations. These operations refer to both the learning activities and the organizational responsibilities.

2) Classroom Like Environment

Primarily, Stochastikon Magister addresses those, who want to solve problems adequately, i.e. by taking into account the inherent uncertainty. Moreover, Stochastikon Magister should be appealing to persons, who are interested in a better understanding of the real world and the evolution. There is no principle background restriction for Magister learners, but students taking part in the programme should have a sufficient (mathematical) educational level.

The Magister Learning Environment is structured to make it similar to a real classroom, because all different kinds of learners are used to it. The functionalities of classroom teaching are simulated in Magister and indicated by the corresponding titles.

- The Stochastics teaching content is divided into courses, modules and units, with the same structure as in a traditional textbook.

- For each learning unit, there are nine learning activities: Target, Content, Example, Literature and FAQ (Frequently Asked Questions) are used for acquiring information, whereas Exercise, Question, Discussion and Test are used for gaining and processing experience. Each activity has its distinguished own effect on learning; all activities in each unit form a small but complete learning process for generating step-by-step new knowledge.

- All learning activities are jointly listed on one page, i.e. they are not sequential or subjected to other restrictions. Learners can start to learn in Magister even without additional instructions, and they can manipulate according to their chosen orders.

The frame of Stochastikon web pages is the same for all subsystems. Each web page is headed by the logo. Below the logo there is the list of subsystems arranged horizontally. On the left hand side there is the sub-menu tree arranged vertically. The rest of the page displays the corresponding content, which accepts different kinds of multimedia formats.

Fig. 1 displays the content page of the 3rd learning unit

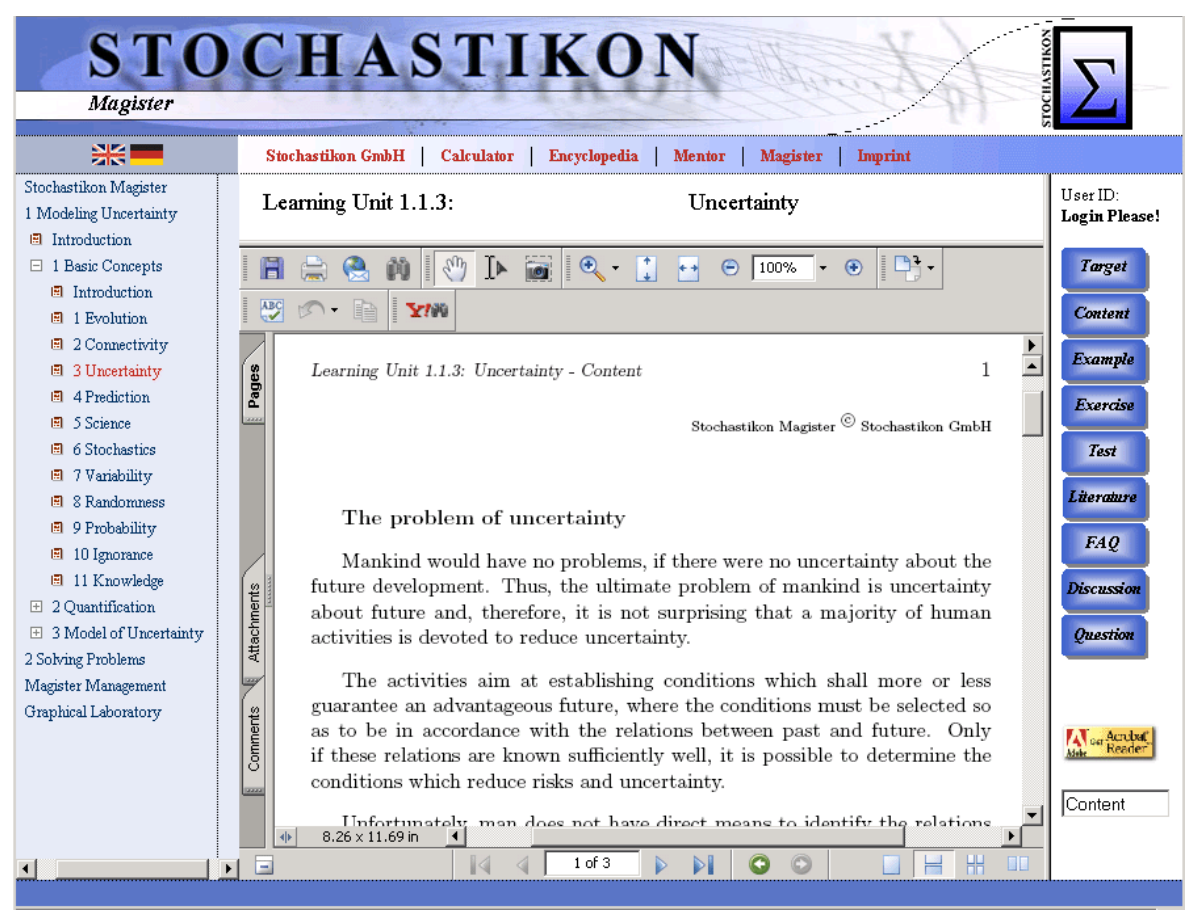

Figure 1. Typical layout of Stochastikon Magister learning units 
of Module 1, Course 1 of Magister. The heading is the learning unit number: '1.1.3' and the unit topic 'Uncertainty'. The current type of learning activity 'Content' is displayed in the activity control panel under all control buttons on the right hand side. Below the headline is the content frame, where the subject matter of the content is displayed by a PDF document.

Magister gets along with only three similar layouts for hundreds of functions. These three layouts serve for the learning units, the learning/course organization and the user information manipulation.

Magister is developed as a pure worldwide web application and runs in all commonly existing web environments. There are no special configuration requirements. The necessary tools are free downloadable software such as Acrobat Reader, Java Virtual Machine, etc. Besides, it is a multilingual system, which can incorporate courses in arbitrarily many languages.

\section{3) The Learning Platform}

Personal guidance and supervision are the most important characteristic features of classroom teaching. Therefore, we not only implemented automatic machine responses to judge and guide the learners' performances, but also provide the possibility of individual personal services. Actually, Magister contains a complete learningprocess support and management system, which guides, helps and documents a learner from the first login, to every achievement, until the learner leaves the system.

- With the registration, a new learner gets a learning plan/suggestion from the instructor in charge according to his background state.

- During the learning process, learners may pose questions and get answers individually from instructors; learners as well as instructors generate topics and join discussions; learners take part in the corresponding tests and get assessments from instructors.

- All traces made by learners in Stochastikon Magister during the whole learning process are recorded and regularly checked by teachers to evaluate and advise the learners of their further learning steps. Moreover, these data also serve the learners to get information about their learning state and knowledge level; learners can feedback to the teachers' instructions and adjust their learning behaviors.

Fig. 2 shows the records of the Learner Cloud's learning progress from 2005-04-22 to 2005-05-05 in Magister. The learning stages of a learner may refer to the learner's learning plan, which constitute the first evaluation.

In Magister, the learner is the master and the source of driving force of his study. Magister is just a platform, which provides sufficient, effective and indispensable supports and services for the learning process.

\section{The E-Learning Platform for Bernoulli Stochastics}

The two seminal papers by von Collani $[2,3]$ are no doubt the cornerstone of both the resumed Bernoulli Stochastics and the Stochastikon development. For Magister, these two articles form the basis for the development of the course contents. Besides, some further aspects had to be taken into account:

- Magister must be a consistent subpart of Stochastikon.

- It must have strong 'Computing Abilities' for introducing stochastic procedures, which have a high mathematical and numerical complexity and pose problems of new and so far unsolved nature.

- It should have available 'Graphical Representations' for supporting the abstract concepts and the stochastic relationships between objects and variables.

- It must support the 'Mathematical Language', which is also the language of Bernoulli Stochastics.

- It must represent the actual developmental and

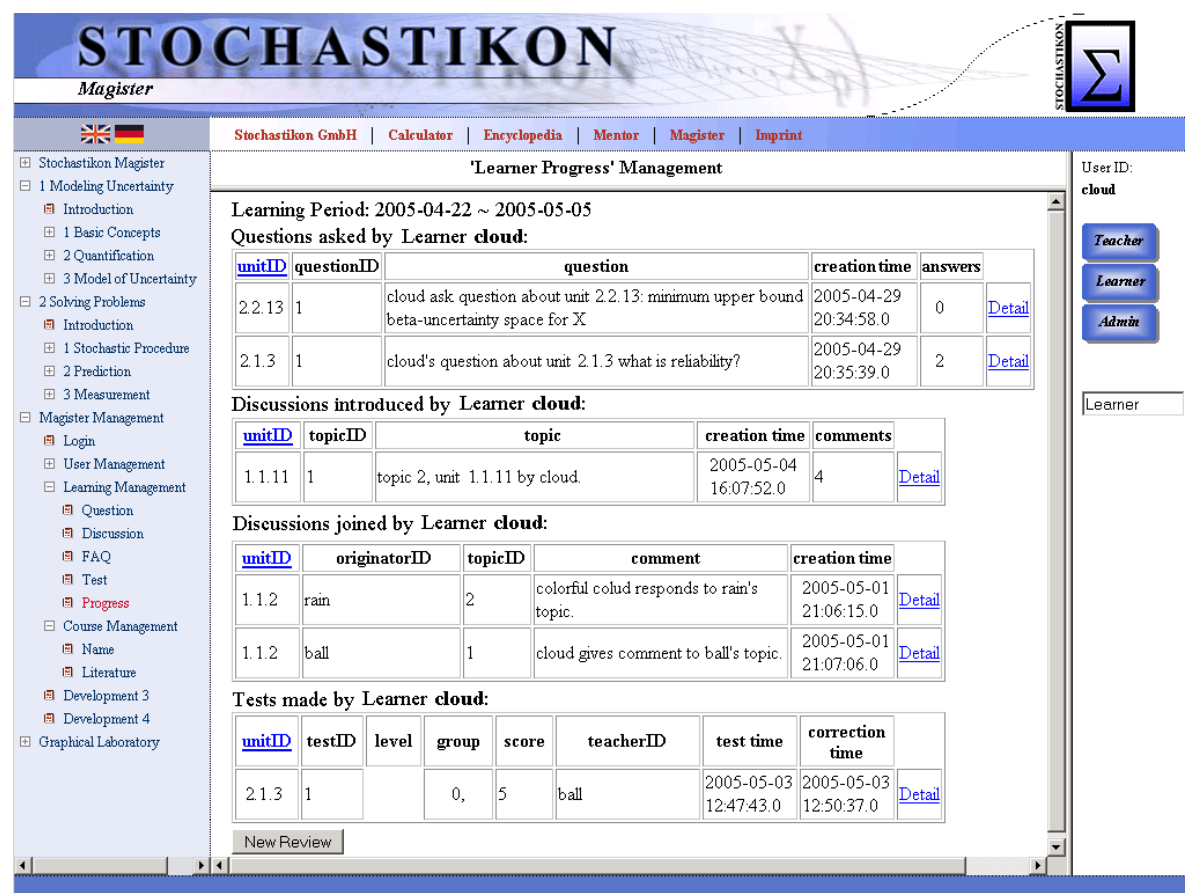

Figure 2. A Learner reviews his Learning Progress during a Learning Stage through Stochastikon Magister 'Progress Management' panel 
educational condition of Bernoulli Stochastics.

- It must satisfy most of the learners, who are not mathematicians, as Bernoulli Stochastics is a science of prediction for handling uncertainty, and uncertainty is a universal problem.

The above requirements led to the decision that Magister had to be completely self-designed and developed under the framework of the Stochastikon project, where the Stochastikon Calculator would be employed for solving difficult mathematical problems and the Stochastikon Graphics for providing the necessary illustrations.

\section{1) Dissemination Stochastics}

Bernoulli Stochastics has the overall aim to convey a realistic view of the world evolution, which necessitates a fundamental change in thinking from deterministic causeeffect relations to dynamic stochastic ones. To this end, the Stochastikon research group is continuously (re-) defining critical concepts and relationships, making clear the differences between stochastics and other alternatives and developing quantitative problem solving procedures. Therefore, everything taught in Magister is new and challenges the traditional education.

To meet the status quo, the nine learning activities designed for each unit are divided into three instructional tiers.

The first level consists of Target, Content, Example and special Introductions of each course and module, which are designed for transferring the predetermined knowledge (knowing what) and develop some anchors for further exploration. For these activities the PDF format is most appropriate, especially for representing mathematical formula.

The second level refers to the activity Exercise, which is partly done by a virtual Graphical Laboratory. The Graphical Laboratory is an online dynamic interactive graphical system for practicing stochastic procedures. It represents a cooperation product of Stochastikon Calculator and Stochastikon Graphics. The exercises, practices and auto responses provided on this level shall clarify the concepts and support the correct applications of the rules to handle some problems (knowing how). Interactive programs are appropriate tools for this didactic task.

As a special kind of learning material, the Graphical Laboratory serves as a means for dealing in a more playful way with stochastic concepts and procedures. Fig. 3 is an interface of the Graphical Laboratory. It shows a sublaboratory for stochastic 'Prediction' procedures with subject to the Binomial distribution. The included graph illustrates a maximum lower bound $\beta$-prediction (the upper part of the figure) with ignorance about the sample size $n$ (from 10 to 18 ) and the known probability of success $p=0.6$. The required confidence level $\beta$ for this prediction is $84 \%$.

The third level includes Literature, Question, Discussion, FAQ and Test. The knowledge imparted on this level is dynamically built-up and organized along with the advancement of Bernoulli Stochastics teaching and learning. These learning activities, except Test, are not mandatory, but only recommended. They promote an open-end experience and foster the construction of new Bernoulli Stochastics knowledge and solutions.

For the first two instructional levels, a system with closed information flow is sufficient as the subjective goal is explicitly and absolutely designed and settled. Closed information flows are more popular than open ones, because the development cost and complexity for the closed information flows are lower. Moreover, there is almost no operating cost for a closed E-Learning environment in contrast to an open one, which might be rather costly. As most E-Learning products are supplements for classroom teaching, closed E-Learning environments are sufficient, because any necessary information beyond the fixed information flow can be handled in the real classroom. As for Magister, for the third instructional level and the purely virtual environment the closed information flow would be completely insufficient.

Thus, the Magister E-Learning platform contains a closed pre-settled information flow and a dynamic open

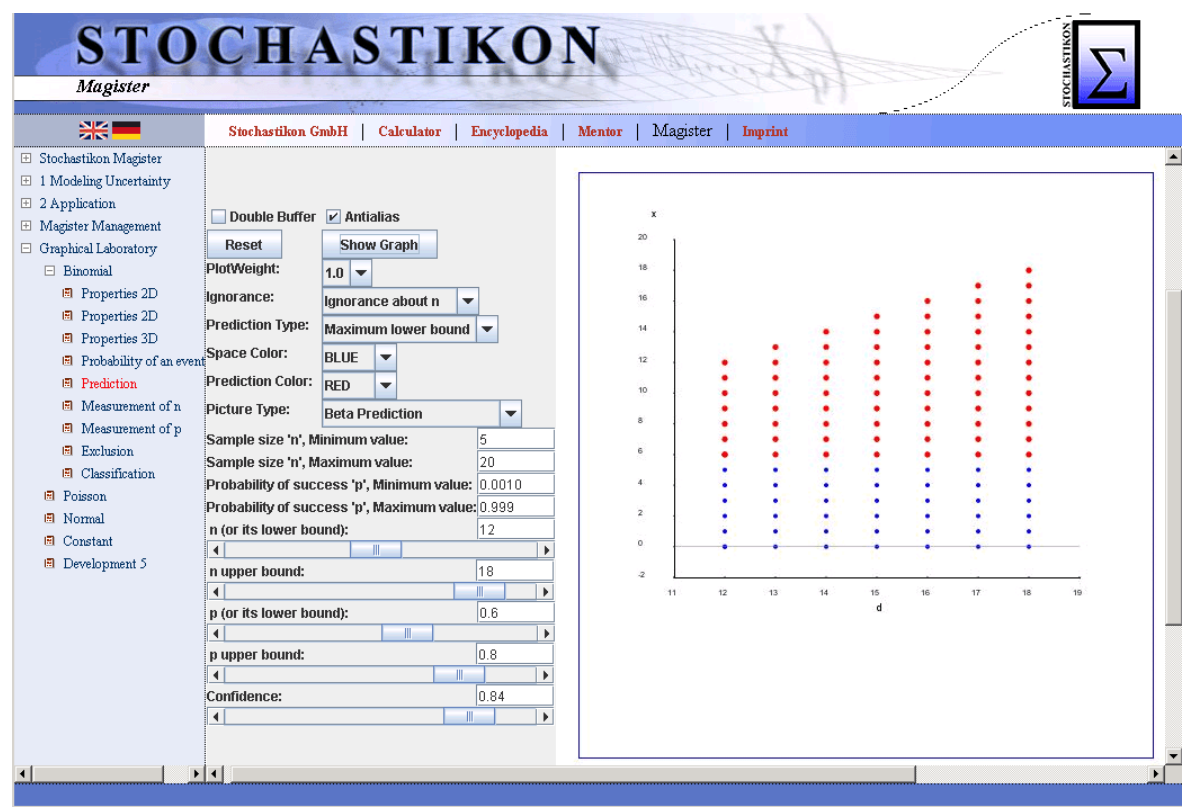

Figure 3. One Interface of the Graphical Laboratory in Stochastikon Magister 
information flow, where the fixed information are seamlessly imbedded into the dynamic information flow during the learning processes.

- The learning content Target, Content, Example and Exercise (including the Graphical Laboratory) constitute the pre-settled and 'automatically generated' information flow. These contents are either pre-assigned (as for example information stored in form of PDF-files) or pre-programmed (as in the case of the Graphical Laboratory).

- The information about User, Literature, Question, Discussion, FAQ, Test, and Learner Progress are open and dynamically changed along with the learners' learning processes.

This three-level instructional scheme is in conformance with general knowledge acquiring process and the actual state of development of Bernoulli Stochastics.

\section{2) Further Development Mode}

In Stochastikon Magister, the learners' questions and discussion contributions can be marked for subsequent use such as creating new frequently asked questions, creating new test questions, etc. Hence the teaching contents and the real learning conditions are combined for providing supplements to the assigned pre-settled teaching content and for providing extensions to the existing teaching material. Thus, Magister not only provides an active learning environment with the possibility of communication, participation and practice, but also a dynamic environment for the creation, improvement and update of the teaching contents. Actually, learning and teaching in Magister collaborate and stimulate each other. Clearly, such a feature can be realized only by an openinformation-flow environment as implemented in Magister.

Stochastikon Magister is a dynamic teaching-learning system, whose growth relies on the co-development and the collective intelligence of both the instructors and learners. The more active the learners take part in the study, the faster Bernoulli Stochastics gets spread, developed and refined.

Since Stochastikon Magister has been started, about three years ago, learners from Germany, Brazil, Poland and China have registered and take the courses. The adjustment and improvement process has continued in accordance with different users' feedbacks, requirements and the operation analysis.

Stochastikon Magister has a lightweight user interface and is based on lightweight development models. Functional modules can be easily improved, added or removed. The whole project is implemented in a costeffective way.

\section{Stochastikon Magister ANd E-LEARning ADVANCED MATHEMATICAL DISCIPLINES}

Stochastikon Magister was designed and implemented for supporting learning and dissemination of a new and highly sophisticated mathematical discipline within a pure Internet environment. The strategies adopted by the Learning Organization System and the Content Management System of Magister are especially meant for presenting novel mathematical contents by appropriately choosing and arranging didactic activities and instructional levels, authoring and displaying mathematical notations and formula, supporting complex calculations, providing interactive dynamic graphical representations, etc. These features constitute the main difference between Magister and other commonly used ELearning products that are generally designed for universal applications.

Magister can therefore serve as a prototype of how to build a web-based virtual classroom for the Internet education in advanced mathematical disciplines.

\section{CONCLUDING REMARKS}

Stochastikon Magister was initiated in 2004, and the software platform was constructed in 2005 . Since then the focus is put on the development of the unprecedented teaching content. At the beginning of 2007 two preliminary courses namely "Modeling Uncertainty" and "Application" were completed and offered online. Parts of the learners are students preparing for an examination in Bernoulli Stochastics without classroom teaching. So far more than 30 students have taken the courses offered by Stochastikon Magister. Most of these students underwent subsequently an oral examination and obtained very good examination results.

Currently, a larger evaluation study is prepared to identify improvements in usability and learnability of Stochastikon Magister.

\section{REFERENCES}

[1] J. Bernoulli, Ars Conjectandi, Basile, 1713.

[2] E. von Collani, "Theoretical Stochastics" in Defining the Science of Stochastics, E. von Collani, Ed. Lemgo: Heldermann Verlag, 2004, pp. 147-174.

[3] E. von Collani, "Empirical Stochastics" in Defining the Science of Stochastics, E. von Collani, Ed. Lemgo: Heldermann Verlag, 2004, pp. 175-213.

[4] A. Binder and X. Zhai, "A Note on Productivity Quality and Reliability and the Aspect of Uncertainty", IAPQR Transactions, vol. 29, no. 2, pp. 83-95, 2004.

[5] E. von Collani and X. Zhai, Stochastics, Beijing: Beijing Publisher Company Group, 2005.

[6] E. von Collani, "Defining and Modeling Uncertainty", Journal of Uncertain Systems, vol. 2, no. 3, pp. 202-211, 2008.

[7] X. Zhai, "Two Old Statistical Methods in a New Stochastic Outfit", Economic Quality Control, vol. 23, no. 1, pp. 29-38, 2008.

[8] E. von Collani, A. Binder, W. Sans, A. Heitmann and K. AlGhazali, "Design Load Definition for Wind Turbines by LEXPOL", Wind Energy, 11, pp. 623-653, 2008. (doi:10.1002/we.290)

\section{AUTHORS}

X. Zhai has a Ph.D. in System Engineering in China and is presently a doctoral student of the Faculty of Mathematics and Computer Science, Würzburg University, Sanderring 2, D-97070 Würzburg, Germany. (e-mail: zhaixiaomin@ hotmail.com).

Dr. E. von Collani is a Professor at the Faculty of Mathematics and Computer Science, Würzburg University, Sanderring 2, D-97070 Würzburg, Germany. (e-mail: collani@mathematik.uni-wuerzburg.de).

Manuscript received 13 October 2008. Published as submitted by the authors. 